\title{
Comprehensive damage evaluation of localized spallation of thermal barrier coatings
}

\author{
Wei-Wei ZHANG ${ }^{a, b, c}$, Guang-Rong LI ${ }^{a}$, Qiang ZHANG ${ }^{a, d}$, Guan-Jun YANG ${ }^{a,}$ \\ ${ }^{a}$ State Key Laboratory for Mechanical Behavior of Materials, School of Materials Science and Engineering, Xi' an \\ Jiaotong University, Xi' an 710049, China \\ ${ }^{b}$ Institute of Publication Science, Chang'an University, Xi' an 710064, China \\ ${ }^{c}$ School of Materials Science and Engineering, Chang'an University, Xi' an 710064, China \\ ${ }^{d}$ AECC Beijing Institute of Aeronautical Material, Beijing 100095, China
}

Received: January 22, 2017; Revised: May 26, 2017; Accepted: May 31, 2017

(C) The Author(s) 2017. This article is published with open access at Springerlink.com

\begin{abstract}
Thermal barrier coatings (TBCs) enable the hot section part to work at high temperatures owing to their thermal barrier effect on the base metal components. However, localized spallation in the ceramic top-coat might occur after long duration of thermal exposure or thermal cycling. To comprehensively understand the damage of the top-coat on the overall hot section part, effects of diameter and tilt angle of the spallation on the temperature redistribution of the substrate and the top-coat were investigated. The results show that the spallation diameter and tilt angle both have a significant effect on the temperature redistribution of the top-coat and the substrate. In the case of the substrate, the maximum temperature increment is located at the spallation center. Meanwhile, the surface (depth) maximum temperature increment, having nothing to do with the tilt angle, increases with the increase of the spallation diameter. In contrast, in the case of the top-coat, the maximum temperature increment was located at the sharp corner of the spallation area, and the surface (depth) maximum temperature increment increases with the increase of both the spallation diameter and the tilt angle. Based on the temperature redistribution of the substrate and the top-coat affected by the partial spallation, it is possible to evaluate the damage effect of spalled areas on the thermal capability of TBCs.
\end{abstract}

Keywords: thermal barrier coatings (TBCs); thermal property; localized spallation; damage evaluation

\section{Introduction}

During past decades, the operating temperature of gas turbine engines has been elevated significantly, with the aim to increase their efficiency. Correspondingly, high temperature durability of the engine components has increased as well [1-4]. Significant advances in the high temperature capability have been achieved through the

* Corresponding author.

E-mail: ygj@mail.xjtu.edu.cn application of nickel-based and cobalt-based superalloys [5-7]. Nonetheless, these monolithicformed alloys are often susceptible to damage by oxidation and hot corrosion, so it is impossible to retain adequate mechanical strength. Moreover, these alloys are unable to bear high service temperature (e.g., above $\left.1000{ }^{\circ} \mathrm{C}[8,9]\right)$. Therefore, thermal barrier coatings (TBCs) are deposited on the hot section components to enhance the temperature capability of the underlying metal substrate. For instance, in the turbine components with suitable internal cooling, temperature drops of 
more than $200 \mathrm{~K}$ can be realized by the TBCs with thicknesses from 200 to $500 \mu \mathrm{m}[8,10]$.

In order to work effectively, the TBCs show excellent thermal barrier effect and high resistance to spallation when exposing to high temperature environment. A typical TBC system often exhibits a multi-layer structure: a metallic bond layer deposited preferentially on the component surface, followed by an adherent ceramic layer providing the thermal insulation effect. Commonly, the ceramic top layer of a TBC deposited by plasma spraying (PS), makes for a lamellar microstructure composing of splats lying parallel to the substrate surface [11]. Moreover, the quantity of intersplat pores is connected with intrasplat cracks, making for a continuous pore network. Consequently, the unique porous structure of the PS top-coat contributes to a low thermal conductivity in the through-thickness direction, as well as high strain tolerance in the in-plane direction.

However, during the service, the TBC system may fail by spallation of the ceramic top-coat, which originates from the extension of those existing microcracks. On one hand, during thermal exposure at high temperatures, a thermally grown oxide (TGO) layer is predominantly formed by alumina [12]. The formation of the TGO plays a crucial role on the failure of the TBCs. The associated failure mechanism often results from the spallation at or close to the TGO layer within either the yttria stabilized zirconia (YSZ) or the bond-coat [13-15]. To begin with, small cracks and separations nucleate at imperfections near the TGO. Once nucleated, the small cracks extend and coalesce, while the TBC may remain attached by remnant ligaments. Finally, spallation occurs when the ligaments are detached over a sufficient area and eventually spalls from the substrate. On the other hand, sintering may lead to the stiffening of the top-coat. Consequently, the strain energy release rate $\left(G_{\mathrm{i}}\right)$ increases significantly. Once $G_{\text {i }}$ reaches its critical value $\left(G_{\text {ic }}\right)$, multilayer delamination may occur in the top-coat [16]. Furthermore, in order to prevent the overheating of the component and to realize further heat protection, numerous cooling holes are drilled throughout the chamber wall [17-19]. These holes enable a protective air film to flow from the external side into the internal face of the TBC-coated chamber. However, with these holes, the ceramic top-coat would be more sensitive to delamination in the leading edge zone with respect to the normal incidence. Regarding the formation of these holes, laser drilling is widely used owing to its non-contact, precise, and reproducible advantages. Nevertheless, it is possible for laser drilling process to damage the vulnerable interface between bond-coat and top-coat $[20,21]$, eventually causing the spallation. In addition, regions of the component will also be subject to the particle impact and foreign object damage, with the result of the spallation.

The service temperature of substrate alloy (i.e., nickel-based superalloy) is often limited to approximately $850-1150{ }^{\circ} \mathrm{C}[8,9]$. The spalled area leads to the direct exposure of the metal to the hot gases, which results in the increase of the substrate temperature. Additionally, the spallation diameter and the tilt angle are two important parameters for temperature redistribution in the TBC system. To sum up, the metal substrate may lose its strength followed by catastrophic failure after the spallation of top-coat. What is worse, the ejected spallation debris might impact and damage the downstream rotating parts. Unfortunately, the above spallation phenomena are unavoidable during the service of TBCs. Therefore, a deep understanding on the damage evaluation and the degradation mechanisms in TBCs has become a major concern. A number of previous reports were related to the damage by spallation. For example, some lifetime prediction models were developed to prevent accidents [22-24], and to repair TBCs on a component with localized spallation [25-31]. Although these reports presented in detail about how to prevent and repair TBCs in case of spallation, little attention had been drawn on evaluating thermal tolerance of the spalled coating when suffering high temperature in service.

In this paper, a structural model was developed to comprehensively evaluate the damage effect of the localized spallation in TBCs. There are too many factors that could affect the failure of TBCs, and we mainly focus on the temperature increase induced by partial spallation, since the temperature increase could accelerate the sintering of top-coat, and have detrimental effect on the metal substrate. The effects of spallation morphology (i.e., diameter and tilt angle) on the temperature redistribution in the substrate and the top-coat were investigated in this paper. Based on this understanding, it would be possible to provide some fundamental supports to forecast accidents and to 
design TBCs with higher reliability and durability.

\section{Numerical approach and procedures}

\section{1 Model basis for finite element analysis}

In order to investigate the spallation-induced temperature redistribution in the substrate and top-coat, finite element analysis (FEA) was used to calculate the temperature across the top-coat. Figure 1(a) shows a TBC with partial spallation in its top-coat [32]. The experimental TBC sample is often cylinder plate like and its structure consists of three layers - a substrate, a bond-coat, and a ceramic top-coat. Therefore, a cylinder plate like 3D model was developed. In addition, spallation areas with different tilt angles and spallation diameters were inserted into the top-coat, as shown in Fig. 1(b). It is obvious that the $3 \mathrm{D}$ cylinder plate like model is an axisymmetric model. Therefore, a 2D analytical unit cell was used in this study, as shown in Fig. 1(c). Parameters of the finite element model were listed in Table 1. It should be noted that, the vertical insulation capacity of TBC should be paid more attention. And hence, for longitudinal direction temperature distribution, 2D temperature distribution can be replaced by $3 \mathrm{D}$. At the same time, to better

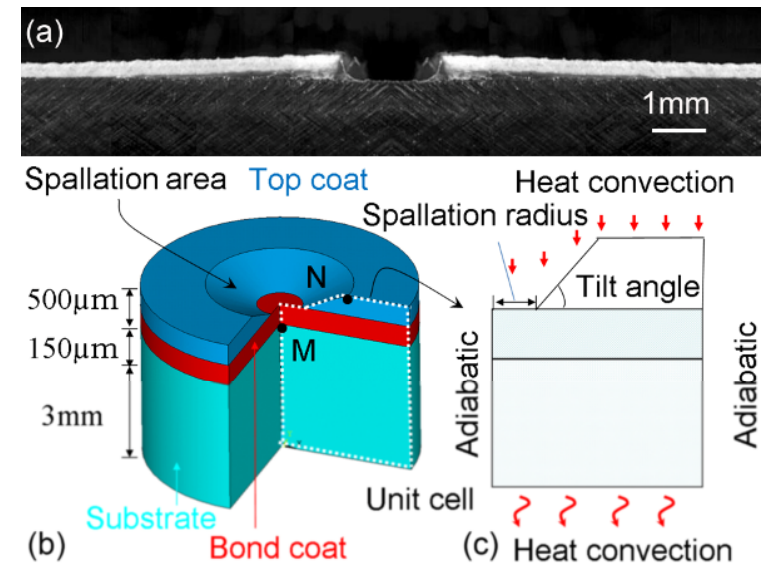

Fig. 1 Developed model used in the finite element simulation: (a) optical photomicrographs of spalled TBCs [32]; (b) the cylinder like model with a spallation area in ceramic top-coat; (c) the simplified 2D axisymmetric analytical model.

Table 1 Parameters of the finite element model used in simulation

\begin{tabular}{|c|c|c|c|}
\hline $\begin{array}{l}\text { Top-coat thickness } \\
\qquad(\mu \mathrm{m})\end{array}$ & $\begin{array}{l}\text { Bond-coat Substrate } \\
\text { thickness thickness } \\
(\mu \mathrm{m}) \quad(\mathrm{mm})\end{array}$ & $\begin{array}{l}\text { Tilt } \\
\text { angle } \\
\left({ }^{\circ}\right)\end{array}$ & $\begin{array}{l}\text { Spallation } \\
\text { diameter } \\
(\mathrm{mm})\end{array}$ \\
\hline 500 & $\begin{array}{ll}150 & 3\end{array}$ & $0-90$ & $0-200$ \\
\hline
\end{tabular}

exhibit the changes of longitudinal and vertical direction temperature distribution by spallation, 2D temperature distribution can be mapped to 3D.

\section{2 Simulation method and procedure}

In this study, the thermal analysis was conducted with the commercially available ANSYS software (afflicted with ANSYS finite element code-APDL). The finite element analysis was conducted in the following steps: (i) create a test model using finite elements; (ii) define and impose the boundary conditions and the material properties; (iii) calculate the temperature distribution in the $2 \mathrm{D}$ model unit cell; and (iv) map the $2 \mathrm{D}$ results to 3D model. The plane 55 elements (four-node element, axisymmetric element) were applied in the model. The plane elements have 1 of freedom, temperature, at each node. The top and bottom of the model were both applied in the convection loading. In particular, at a gas temperature $>1200{ }^{\circ} \mathrm{C}$, the contribution from thermal radiation can be up to $30 \%$ or more $[33,34]$. However, it should be noted that, unlike micro defect, thermal radiation is insensitive to the change of the macro-damage in the top-coat. In other words, whether the spallation is introduced or not, the thermal radiation is identical. Hence, as a simplification, heat transfer by radiation was neglected. Moreover, the convection has to be taken into account when the Grashof number ( $\mathrm{Gr}$ ) exceeds a value of 1000 [35]. It can be estimated that the convection may be significant when the pore size is large than $10 \mathrm{~mm}$. Therefore, it is reasonable to neglect the convective effect, since the pores in $\mathrm{TBC}$ are approximately from tens of nanometers to tens of micrometers [36]. To sum up, only the conduction was considered for the heat transfer through top-coat in this study. Adiabatic boundary condition was applied to the left and right sides. The substrate and the bond-coat were assumed to be isotropic and homogeneous, while the top-coat was anisotropy. Consequently, in-plane and in-depth thermal conductivities of the top-coat were selected to be 1.5 and $1.0 \mathrm{~W} \cdot \mathrm{m}^{-1} \cdot \mathrm{K}^{-1}$ [37], respectively. The boundary conditions are illustrated in Table 2. It is important to note that the thermal conductivities of bond-coat and substrate are highly temperature dependent. For example, in the case of NiCoCrAlY, when the temperature increases from 300 to $900 \mathrm{~K}$, and to $1400 \mathrm{~K}$, the thermal conductivity increases from 6.4 to $10.2 \mathrm{~W} \cdot \mathrm{m}^{-1} \cdot \mathrm{K}^{-1}$, and to $15 \mathrm{~W} \cdot \mathrm{m}^{-1} \cdot \mathrm{K}^{-1}[39]$, respectively. It is noted that the thermal conductivities 
Table 2 Thermal parameters used in simulation

\begin{tabular}{|c|c|c|c|c|}
\hline & $\begin{array}{l}\text { Thermal conductivity } \\
\qquad\left(\mathrm{W} \cdot \mathrm{m}^{-1} \cdot \mathrm{K}^{-1}\right)\end{array}$ & & $\begin{array}{c}\text { Heat } \\
\text { convection } \\
\text { coefficient } \\
\left(\mathrm{W} \cdot \mathrm{m}^{-2} \cdot \mathrm{K}^{-1}\right)\end{array}$ & $\begin{array}{c}\text { Environmental } \\
\text { temperature } \\
(\mathrm{K})\end{array}$ \\
\hline $\begin{array}{l}\text { Top-coa } \\
\text { (in-plane }\end{array}$ & $\begin{array}{l}\text { t Top-coat Bond-coat } \\
\text { (out-plane) }\end{array}$ & $\begin{array}{l}\text { ubstrate } \\
\text { [39] }\end{array}$ & $\begin{array}{c}\text { Top } \\
\text { of } \begin{array}{c}\text { Bottom } \\
\text { of } \\
\text { model model }\end{array}\end{array}$ & $\begin{array}{cc}\text { Top } & \text { Bottom } \\
\text { of } & \text { of } \\
\text { model } & \text { model }\end{array}$ \\
\hline 1.5 & 1.0 & 20 & $\begin{array}{ll}1740 & 815 \\
\end{array}$ & $\begin{array}{ll}1423 & 673 \\
\end{array}$ \\
\hline
\end{tabular}

of bond-coat and substrate are always larger than that of the top-coat. It is shown that the temperature distribution of layers is mainly affected by top-coat. Although the specific value changes with temperature, the overall temperature distribution induced by spallation damage would be consistent. Hence, in order to facilitate the calculation, the thermal conductivities of bond-coat and substrate are average values for the entire temperature range. In order to increase the accuracy of the numerical simulation, the mesh is fine enough. The simulation results were extracted from the ANSYS visualization.

\section{Results}

\section{1 Temperature distributions for two limit cases}

Figure 2 shows the temperature distribution across the TBC system under two limit cases, i.e., with top-coat (i.e., no spallation) and without top-coat (i.e., complete spallation). No spallation and the complete spallation are two limit cases corresponding to the normal coating (i.e., the spallation diameter is 0 ) and the completely spalled coating (i.e., the spallation diameter tends to be infinite), respectively. It can be seen that the temperatures of both models decrease in the depth direction. However, the temperature curves (see Fig. 2(e)) are different from the interfaces of three layers. The variation rate of temperature curves decreases along top-coat, bond-coat, and substrate, resulted from different thermal conductivities of three materials (see Table 2). With no spallation, it is clearly found that the surface temperature of top-coat and substrate is 1423 and $1273 \mathrm{~K}$ respectively (namely, the heat insulation temperature of top-coat is $150 \mathrm{~K}$ ). However, the temperature increases to $1375 \mathrm{~K}$ in the case without top-coat. This is the upper limit of substrate surface temperature in this model.

\section{2 Temperature redistributions under different spallation diameters}

Figure 3 shows the effect of spallation diameter on the temperature redistribution across the TBC system. Given that 3D graphs present the temperature distribution in in-plane and out-plane directions simultaneously, both $2 \mathrm{D}$ and $3 \mathrm{D}$ temperature distributions are given in this section. In order to facilitate the observation, we define the red area as a high-temperature zone. As can be seen from Fig. 3(a), there is no high-temperature zone in the case of the no spallation. Meanwhile, the isotherms are nearly linear, with uniform gradient distribution (see Fig. 3(a-3)). When spallation diameter increases to $0.5 \mathrm{~mm}$ (see Fig. 3(b)), the high-temperature zone begins to appear in top-coat (see Fig. 3(b-3)). The initial isotherms near the spallation area turn to be slightly bended. With the
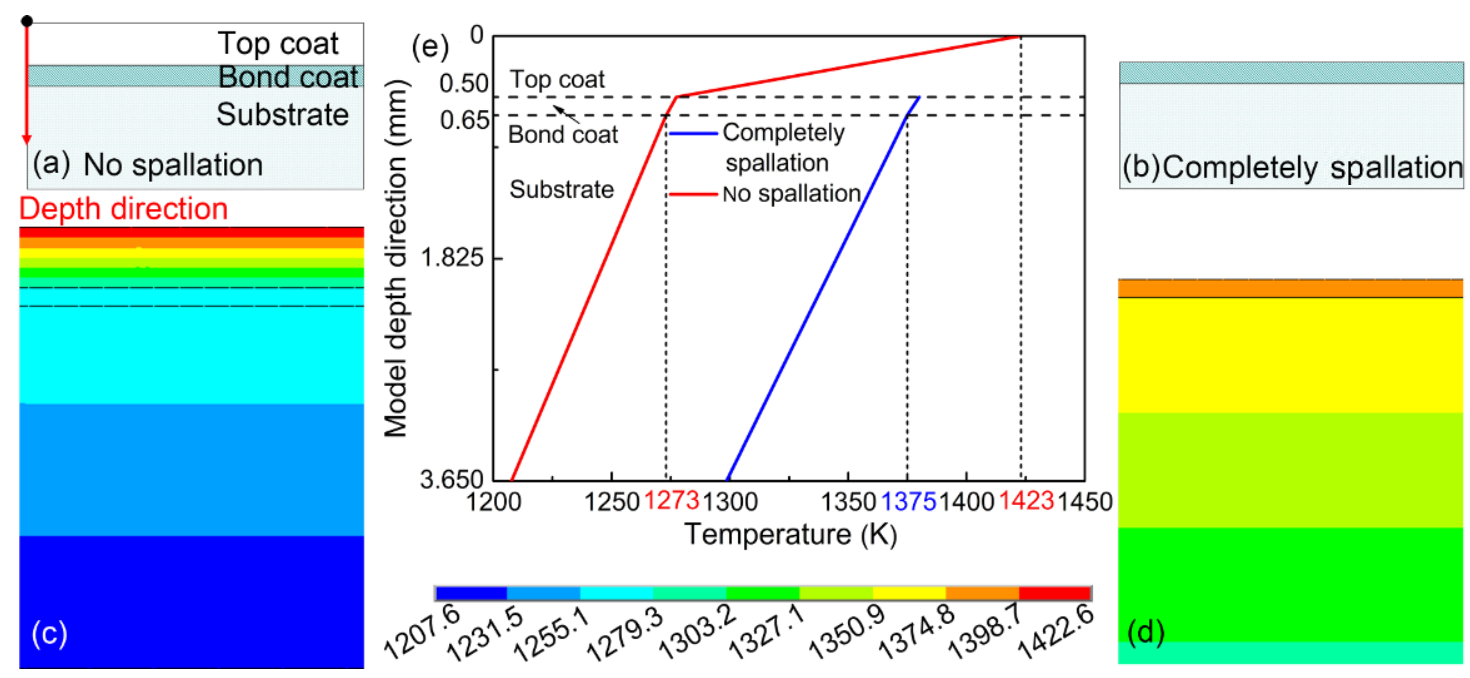

Fig. 2 Temperature distributions across a TBC system under different cases: (a) and (c) are two limit cases with no spallation and complete spallation, respectively; (b) and (d) are the temperature distribution corresponding to (a) and (c), respectively. (e) Temperature distribution along the depth direction for these two cases. 


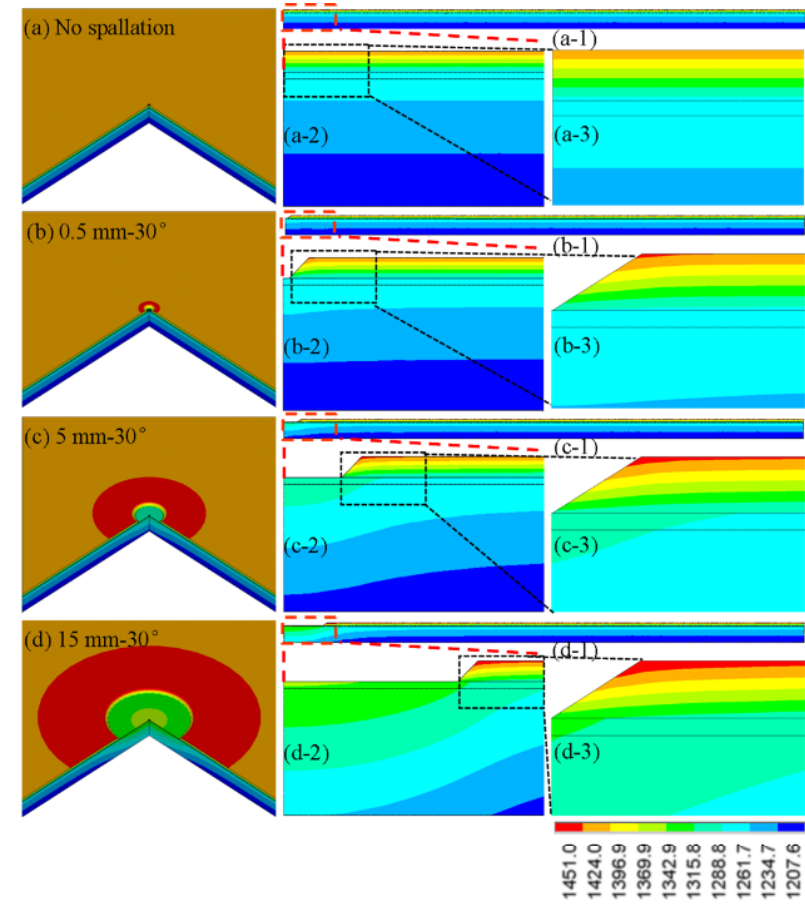

Fig. 3 Temperature distribution under different spallation diameters with a identical tilt angle $30^{\circ}$ : (a) $0 \mathrm{~mm}$ (no spallation); (b) $0.5 \mathrm{~mm}$; (c) $5 \mathrm{~mm}$; and (d) $15 \mathrm{~mm}$. (a-1)-(d-1) are the $2 \mathrm{D}$ temperature distribution corresponding to the model (a)-(d), respectively. (a-2)-(d-2) are detailed indications of the red dashed frame. (a-3)-(d-3) are detailed indications of the black dashed frame.

increase of the spallation diameter, the range of high-temperature zone expands gradually and the isotherms are highly bended. The temperature redistribution trend in substrate is similar to that in the top-coat. To sum up, temperature distribution of the substrate and the top-coat is affected significantly by the spallation diameters. In detail, the temperatures (near the spallation area) of the substrate and the top-coat increase with the increase of spallation diameters.

\section{3 Temperature redistributions under different tilt angles}

Figure 4 shows the effect of tilt angle on the temperature redistribution across the TBC system. Compared with the case of no spallation (see Fig. 4(a)), the isotherms of the other models (see Figs. 4(b)-4(d)) are nonlinear to some extent, owing to the existence of spallation area. It is consistent with the results in Section 3.2. As can be seen from Figs. 4(b)-4(d), with the increase of tilt angle, the substrate temperature distribution seems unaffected, while the temperature of top-coat changes significantly. In brief, different from

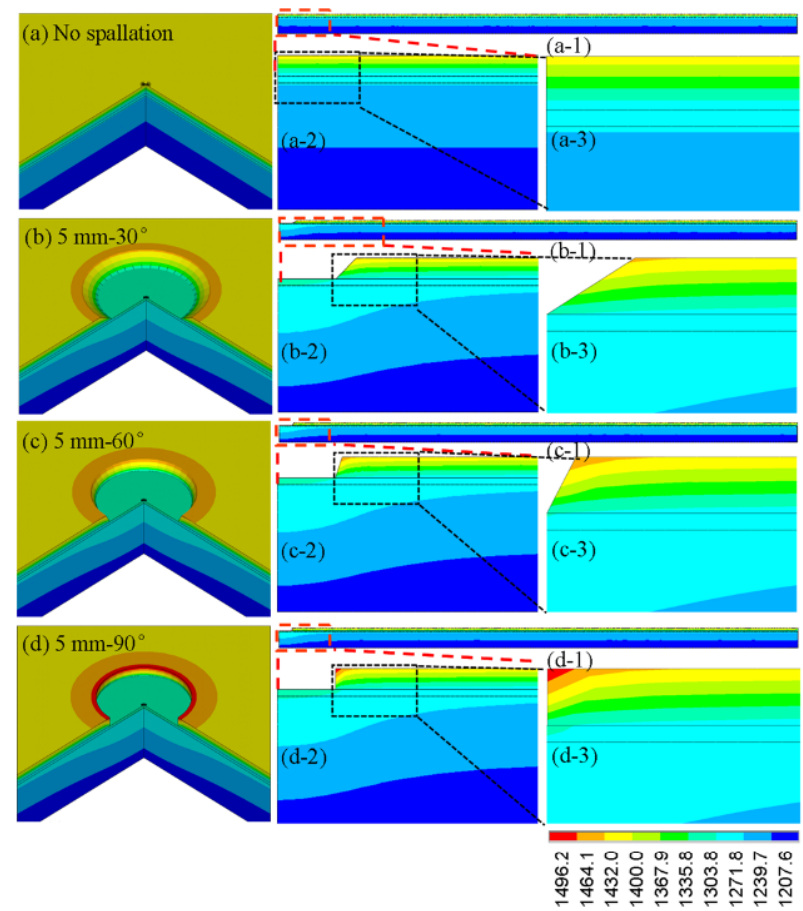

Fig. 4 Temperature distribution under different tilt angles with a identical spallation diameter $5 \mathrm{~mm}$ : (a) $0^{\circ}$ (no spallation); (b) $30^{\circ}$; (c) $60^{\circ}$; and (d) $90^{\circ}$. (a-1)-(d-1) are the $2 \mathrm{D}$ temperature distribution corresponding to the model (a)-(d), respectively. (a-2)-(d-2) are detailed indications of the red dashed frame. (a-3)-(d-3) are detailed indications of the black dashed frame.

the spallation diameter, the tilt angle has much slight effect on the substrate temperature distribution.

Figure 5 shows the temperature distribution in substrate and top-coat with a spallation diameter of $5 \mathrm{~mm}$ and a tilt angle of $90^{\circ}$. It can be seen that the surface temperatures of substrate and top-coat are at their peak points at the center of spallation area, whereas it decreases dramatically as being away from the center, and eventually decreases to the surface temperature presented in the no spallation model. In contrast, the deep temperatures of substrate or top-coat decrease continuously. The above results are also generally applicable to other cases with different spallation dimensions. It should be noted that the temperatures on thermal barrier coatings with no spallation, along the surface or the in-depth direction, change linearly. However, with the spallation, the varying trend tends to be nonlinear.

\section{Discussion}

After reviewing literatures, it is easy to find that numerous researchers pay close attention to the damage 

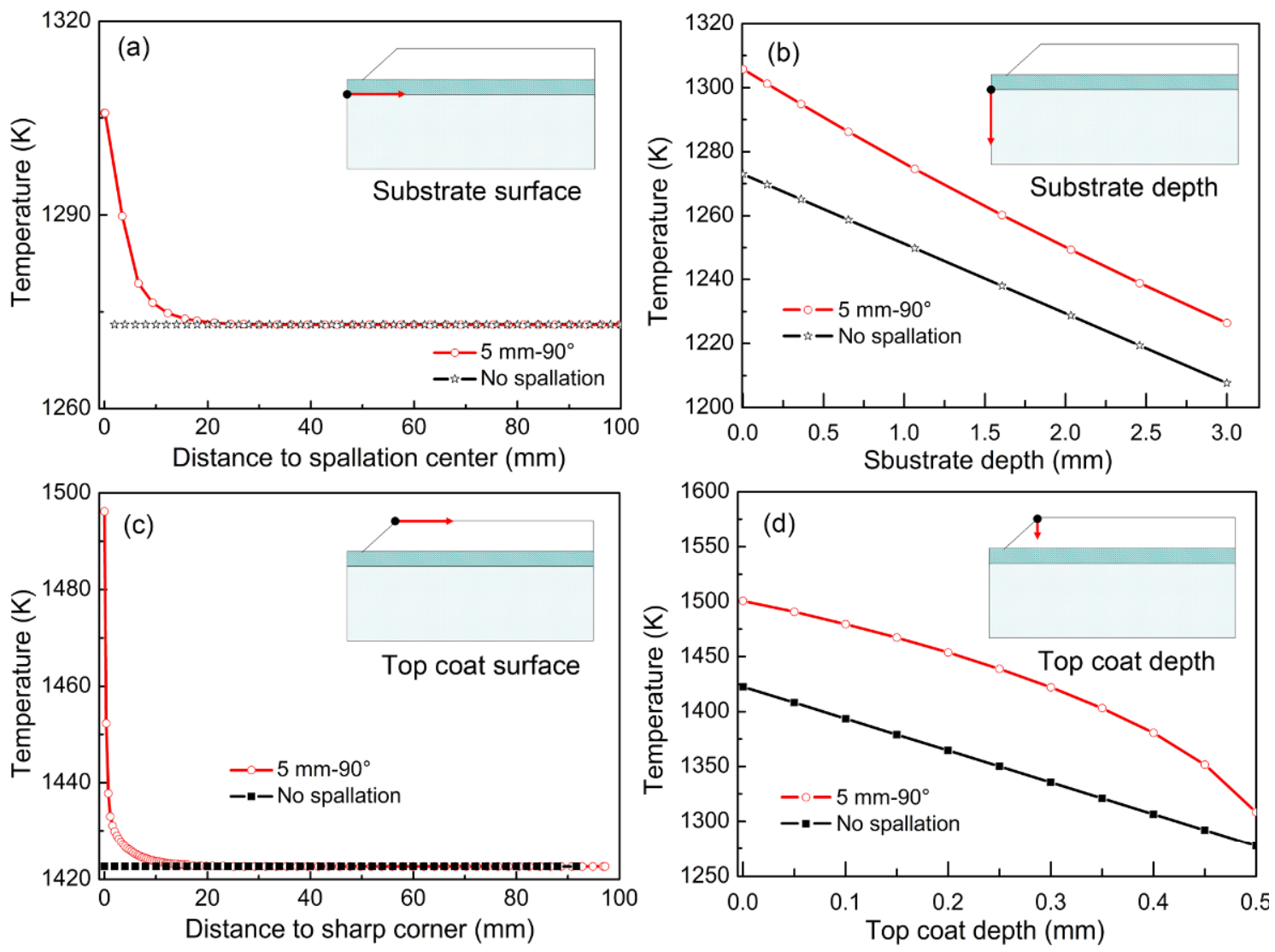

Fig. 5 Temperature distribution in TBCs: (a) along substrate surface direction; (b) along substrate depth direction; (c) along top-coat surface direction; and (d) along top-coat depth direction. The spallation diameter is $5 \mathrm{~mm}$ and the tilt angle is $90^{\circ}$.

by spallation. The relevant research concentrates on three aspects as follows. The first is to describe the specific mechanisms leading to the failure, with the purpose of providing a reference for material upgradation $[14,15]$. The second is to predict lifetime to prevent accident [22-24]. The third is to repair a TBC with a component that has suffered localized spallation [25-31]. Although these reports presented in detail about how to prevent and to repair TBC in case of spallation, little attention has been paid to evaluating thermal tolerance of the spalled coating when suffering high temperatures in operation. To comprehensively understand the damage of top-coat spallation on the overall hot section part, the effects of spallation morphology (i.e., diameter and tilt angle) on the temperature redistribution of the substrate and the top-coat were investigated.

\section{1 Temperature increment in substrate}

In order to provide a more intuitive and universally applicable approach to evaluate the damage effect of spallation, we take temperature increment into consideration in this paper. The temperature increment is defined as the temperature differences of the substrate and the top-coat with and without spallation. For example, with a spallation of $5 \mathrm{~mm}-90^{\circ}$, the temperature increment value can be obtained by the difference between the red curve and the gray curve at each abscissa value (see Fig. 5).

In this paper, the temperature increments of both the substrate and the top-coat along surface and depth direction were investigated. The temperatures at different interfaces in the initial model without spallation (i.e., the sources of the gray line in Fig. 5) are as follows. According to Fig. 2(c), the temperature isotherm with no spallation is linear. Therefore, the surface temperature of substrate keeps constant at $1273 \mathrm{~K}$ (see Fig. 2(e)) with increase of the distance to spallation center (see Fig. 5(a)). Similarly, the surface temperature of top-coat remains unchanged at $1423 \mathrm{~K}$ (see Fig. 2(e)) with increase of the distance to sharp corner (see Fig. 5(c)). The temperature of the substrate along the depth direction in Fig. 5(b) corresponds to the temperature in Fig. 2(e) for model depth ranging from 0.65 to $3.65 \mathrm{~mm}$, whereas the temperature of the 
top-coat along the depth direction refers to the model depth ranging from 0 to $0.65 \mathrm{~mm}$ (see Fig. 5(d)).

Figure 6 illustrates the effect of spallation parameters (i.e., the diameter and the tilt angle) on the temperature increment in substrate along its surface (see Fig. 6(a)) and in-depth directions (see Fig. 6(b)). It can be seen from Fig. 6(a) that the temperature increment decreases with increase of the distance to the spallation center. It means that the spallation has a severe effect on the area near the spallation center and that the effect gradually decreases with the increase of the distance from the center. Therefore, the maximum temperature increment along substrate surface appears at the center of spallation area. Furthermore, near the spallation center, the temperature increment along the substrate surface increases with the growth of spallation diameter under an identical tilt angle. For example, with the same distance to spallation center $(0 \mathrm{~mm})$ and the same tilt angle $\left(30^{\circ}\right)$, the temperature increment increases from 8.1 to $31.3 \mathrm{~K}$, and to $68.0 \mathrm{~K}$ when the spallation diameter grows from 0.5 to $5 \mathrm{~mm}$, and to $15 \mathrm{~mm}$, respectively. Actually, the temperature increment along the substrate surface will not increase until the spallation diameter reaches the high limit value, which refers to the case without top-coat (102 K, see Fig. 2(e)). After that, when the spallation diameter continues to increase, a platform turns up in the temperature increment curve. The figure inserted in Fig. 6(a) shows the temperature increment with the spallation of $70 \mathrm{~mm}-90^{\circ}$.

It can also be seen from Fig. 6(a) that the temperature increment curves in the cases with spallations of $5 \mathrm{~mm}-30^{\circ}, 5 \mathrm{~mm}-60^{\circ}$, and $5 \mathrm{~mm}-90^{\circ}$ are almost overlapped. The tilt angle has little effect on the temperature increment along substrate surface direction. As shown in Fig. 6(b), the spallation diameter has a similar effect on the temperature increment of the substrate along the depth direction, i.e., it increases with the spallation diameter and remains unaffected by the tilt angles. Moreover, the maximum temperature increment along the longitudinal direction appears on the substrate surface. Based on Fig. 6(a) and Fig. 6(b), it is worth noting that the maximum temperature increments along the substrate surface and its in-depth direction locate at the spallation center. In other words, the maximum temperature would appear at the spallation center of substrate.

Figure 6(c) shows evolution of the maximum temperature increment in substrate as a function of the spallation parameters, i.e., the tilt angle and the
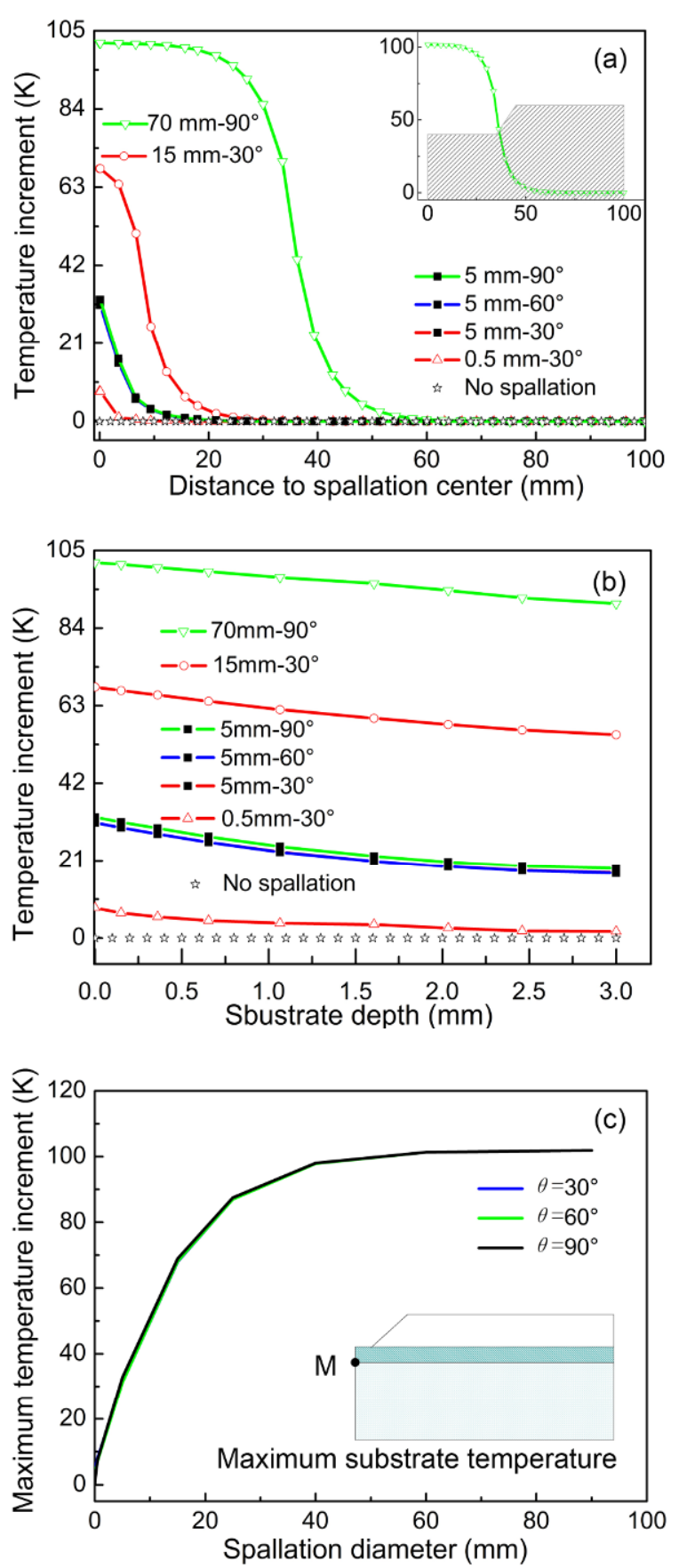

Fig. 6 Temperature increments along the substrate surface (a) and its in-depth directions (b) with different spallation dimensions. (c) is the maximum temperature increment in substrate surface (corresponding to the spallation area center, point $\mathrm{M}$ ) as a function of the tilt angle and the spallation diameter.

diameter. As shown in Fig. 6(c), the maximum temperature increment in substrate surface, having nothing to do with the tilt angle, is strongly dependent with the spallation diameter. In detail, the maximum temperature increment increases with the increase of the spallation diameter. The increase trend is fast at first, 
gradually slows down, and finally tends to be stable. The initial occurrence of maximum temperature increment $(102 \mathrm{~K})$ corresponds to the diameter of $70 \mathrm{~mm}$. Subsequently, it maintains at $102 \mathrm{~K}$. A smaller spallation diameter corresponds to better thermal durability of spalled coatings. In contrast, a larger spallation diameter demonstrates a higher possibility for the failure induced by substrate melting. Therefore, there is a gradually increasing influence of substrate overheating damage as the spallation diameter is less than $70 \mathrm{~mm}$. Otherwise the substrate temperature increment remains constant of $102 \mathrm{~K}$.

To sum up, it can be concluded that the spallation diameter is harmful to the substrate, while the tilt angle has little effect on the substrate damage. The extent of damage increases with the increasing spallation diameter. For a given spallation area, the spallation diameter can be determined, and then the temperature increment in substrate can be estimated. In brief, the temperature distribution along the substrate surface and in-depth directions, as well as the maximum temperature increment is illustrated in Figs. 6(a), 6(b), and $6(\mathrm{c})$, respectively. Furthermore, the acceptable temperatures at different positions of the substrate were prescribed. Therefore, in terms of Fig. 6, the temperature redistribution in substrate induced by spalled TBC can be estimated. Whether components can be in service further is assessed as well.

\section{2 Temperature increment in top-coat}

Figure 7 shows the effect of spallation parameters on the temperature increment along the top-coat surface (Fig. 7(a)) and its in-depth directions (Fig. 7(b)). As shown in Fig. 7(a), it can be seen that the decrease of temperature increment can be divided into two stages: a rapid decrease at the initial following by a more gentle decrease stage. Near the spallation area center (the first stage), the surface temperature increment decreases with the increase of spallation diameter (red line) and tilt angle (black spot). When the distance to spallation area center continues increasing (the second stage), the temperature increment seems unaffected by the tilt angle or spallation diameter. For instance, under the same tilt angle $\left(30^{\circ}\right)$ and the same distance as the sharp corner (about $1.5 \mathrm{~mm}$ ), the temperature increment increases from 1.0 to $5.7 \mathrm{~K}$, and to $14.1 \mathrm{~K}$ when the
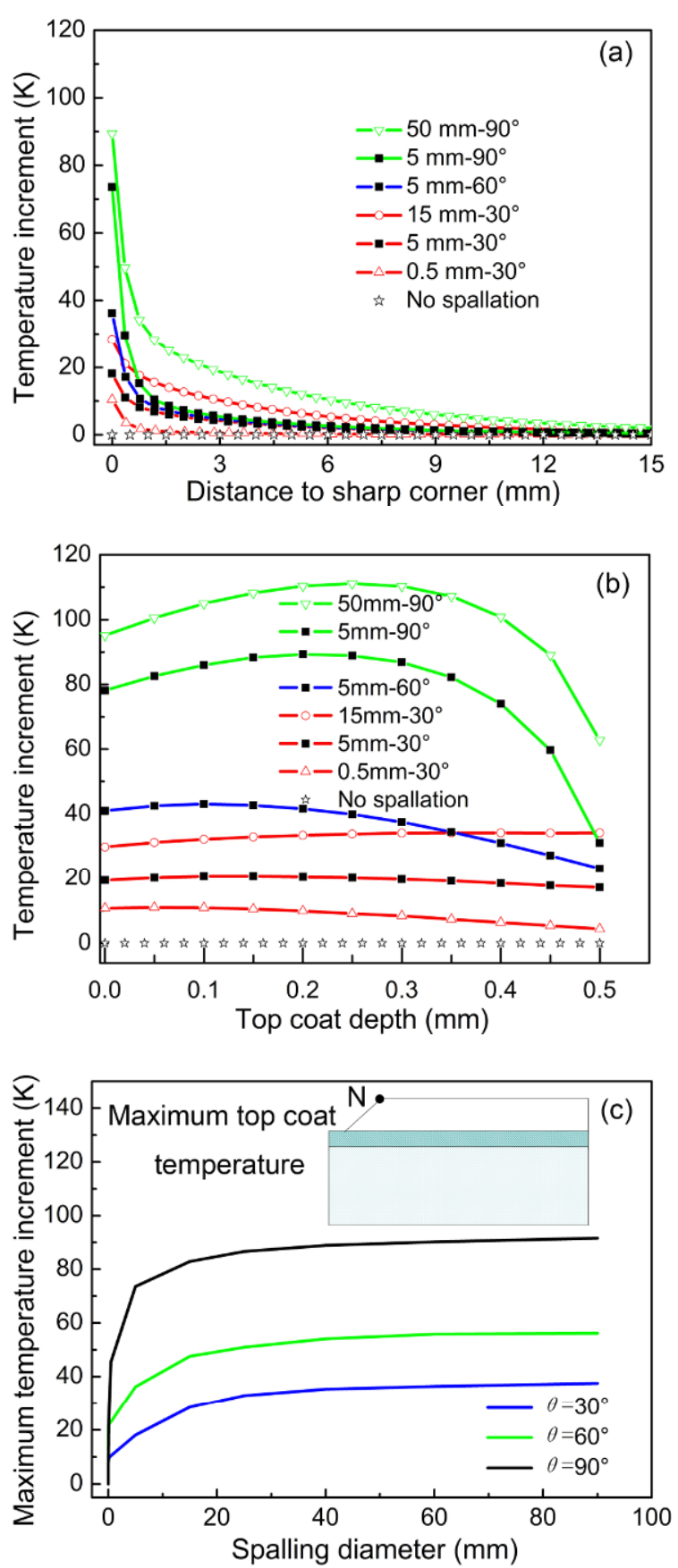

Fig. 7 Temperature increments along the top-coat surface (a) and its in-depth directions (b) with different spallation dimensions. (c) is the maximum temperature increment in top-coat surface (corresponding to the sharp corner of top-coat, point $\mathrm{N}$ ) as a function of the tilt angle and the spallation diameter.

spallation diameter increases from 0.5 to $5 \mathrm{~mm}$, and to $15 \mathrm{~mm}$, respectively. There is a similar evolution trend as a function of tilt angle under the same spallation diameter. In brief, the spallation diameter and the tilt angle both have significant effects on the temperature increment of the top-coat surface. It is not hard to see 
that the maximum temperature increment of top-coat appeared at the sharp corner of top-coat.

Figure 7(b) shows the temperature increment along the in-depth direction of top-coat. Similar trends can be found despite of the spallation dimensions (see Fig. 6(b)). The only difference is that the temperature increment of the spallations of $5 \mathrm{~mm}-90^{\circ}$ and $50 \mathrm{~mm}-90^{\circ}$ slightly increases along top-coat depth. However, it is important to note that the temperature curve continues to decrease along top-coat depth. That may be resulted from the nonlinear change of the temperature along in-depth direction (see Fig. 5(d)). Figure 7(c) shows the maximum temperature increment at the point $\mathrm{N}$. It is clear that the maximum temperature increment of the top-coat is affected comprehensively by the spallation diameter and the tilt angle. It is noted that, with the radius of the damaged zone from 0.5 to $200 \mathrm{~mm}$ and the thickness of the top-coat being $0.5 \mathrm{~mm}$, the inclination of the edge has little influence on the large-scale damaged zone. Therefore, the tilt angle would have a significant effect only when the spallation area is small enough.

To sum up, both the spallation diameter and the tilt angle have a detrimental effect on the top-coat when spallation occurs, as the temperature increment is significantly affected by the spallation dimensions. Furthermore, when spallation occurs, it would be ready to determine the spallation diameter and the tilt angle. Consequently, the corresponding temperature increments of the top-coat at different positions can be estimated. Based on this, the sintering-induced stiffening degrees of top-coat at different regions can be determined to evaluate the corresponding deterioration of top-coat.

\section{Conclusions}

During thermal service, the spallation of the ceramic top-coat in TBCs may result in the degradation of the TBC system, as the temperature of both the substrate and the top-coat may rise. Subsequently, there may exist further delamination of the top-coat and severe strength loss of the substrate. In this paper, the effects on spallation were investigated by finite element analysis method. Temperature changes in both the substrate and the top-coat were evaluated by different spallation tilt angles (from $0^{\circ}$ to $90^{\circ}$ ) and diameters (from 0 to $200 \mathrm{~mm}$ ). The results show that the temperature increments along the substrate surface and its in-depth directions are affected by the spallation diameter significantly. However, the temperature increment of substrate seems unaffected by the tilt angle. In contrast, both the tilt angle and the spallation diameter have distinct effects on the temperature increment of the top-coat, along the surface or the in-depth direction. Based on the temperature distributions in the substrate and the top-coat, it is possible to estimate the damage effect when spallation occurs.

\section{Acknowledgements}

This work is supported by the National Basic Research Program of China (No. 2013CB035701), the National Natural Science Foundation of China (Grant No. 51671159), the Fundamental Research Funds for the Central Universities, and the National Program for Support of Top-notch Young Professionals.

\section{References}

[1] Clarke DR, Oechsner M, Padture NP. Thermal-barrier coatings for more efficient gas-turbine engines. MRS Bull 2012, 37: 891-898.

[2] Hardwicke CU, Lau Y-C. Advances in thermal spray coatings for gas turbines and energy generation: A review. J Therm Spray Techn 2013, 22: 564-576.

[3] Chen X, Zhang H, Zhang H, et al. $\mathrm{Ce}_{1-x} \mathrm{Sm}_{x} \mathrm{O}_{2-x / 2}$-A novel type of ceramic material for thermal barrier coatings. $J A d v$ Ceram 2016, 5: 244-252.

[4] Greil P. Generic principles of crack-healing ceramics. $J A d v$ Ceram 2012, 1: 249-267.

[5] Wu H, Li Q. Application of mechanochemical synthesis of advanced materials. $J$ Adv Ceram 2012, 1: 130-137.

[6] Levi CG. Emerging materials and processes for thermal barrier systems. Curr Opin Solid St M 2004, 8: 77-91.

[7] Pollock TM, Tin S. Nickel-based superalloys for advanced turbine engines: chemistry, microstructure and properties. J Propul Power 2006, 22: 361-374.

[8] Lima RS, Marple BR. Nanostructured YSZ thermal barrier coatings engineered to counteract sintering effects. Mat Sci Eng A 2008, 485: 182-193.

[9] Caron P, Khan T. Evolution of Ni-based superalloys for single crystal gas turbine blade applications. Aerosp Sci Technol 1999, 3: 513-523.

[10] Padture NP, Gell M, Jordan EH. Thermal barrier coatings for gas-turbine engine applications. Science 2002, 296: 280-284.

[11] Vaßen R, Jarligo MO, Steinke $\mathrm{T}$, et al. Overview on 
advanced thermal barrier coatings. Surf Coat Technol 2010, 205: 938-942.

[12] Rabiei A, Evans AG. Failure mechanisms associated with the thermally grown oxide in plasma-sprayed thermal barrier coatings. Acta Mater 2000, 48: 3963-3976.

[13] Evans AG, Mumm DR, Hutchinson JW, et al. Mechanisms controlling the durability of thermal barrier coatings. Prog Mater Sci 2001, 46: 505-553.

[14] Schlichting KW, Padture NP, Jordan EH, et al. Failure modes in plasma-sprayed thermal barrier coatings. Mat Sci Eng $A$ 2003, 342: 120-130.

[15] Nissley DM. Thermal barrier coating life modeling in aircraft gas turbine engines. $J$ Therm Spray Techn 1997, 6: 91-98.

[16] Shinozaki M, Clyne TW. A methodology, based on sintering-induced stiffening, for prediction of the spallation lifetime of plasma-sprayed coatings. Acta Mater 2013, 61: 579-588.

[17] Voisey KT, Clyne TW. Laser drilling of cooling holes through plasma sprayed thermal barrier coatings. Surf Coat Technol 2004, 176: 296-306.

[18] Guinard C, Montay G, Guipont V, et al. Residual stress analysis of laser-drilled thermal barrier coatings involving various bond coats. $J$ Therm Spray Techn 2015, 24: 252-262.

[19] Girardot J, Schneider M, Berthe L, et al. Investigation of delamination mechanisms during a laser drilling on a cobalt-base superalloy. J Mater Process Tech 2013, 213: 1682-1691.

[20] Kamalu J, Byrd P, Pitman A. Variable angle laser drilling of thermal barrier coated nimonic. J Mater Process Tech 2002, 122: 355-362.

[21] Corcoran A, Sexton L, Seaman B, et al. The laser drilling of multi-layer aerospace material systems. J Mater Process Tech 2002, 123: 100-106.

[22] Busso EP, Wright L, Evans HE, et al. A physics-based life prediction methodology for thermal barrier coating systems. Acta Mater 2007, 55: 1491-1503.

[23] Beck T, Herzog R, Trunova O, et al. Damage mechanisms and lifetime behavior of plasma-sprayed thermal barrier coating systems for gas turbines-Part II: Modeling. Surf Coat Technol 2008, 202: 5901-5908.

[24] Trunova O, Beck T, Herzog R, et al. Damage mechanisms and lifetime behavior of plasma sprayed thermal barrier coating systems for gas turbines-Part I: Experiments. Surf Coat Technol 2008, 202: 5027-5032.

[25] Stowell WR, Johnson RA, Skoog AJ, et al. Method for repairing a thermal barrier coating and repaired coating formed thereby. U.S. Patent 6,413,578. 2002.

[26] Nagaraj BA, Mannava S, Gupta BK. Method for repairing a thermal barrier coating. U.S. Patent 5,723,078. 1998.

[27] Draghi PJ, Wrabel P. Repair of gas turbine engine component coated with a thermal barrier coating. U.S.
Patent 5,972,424. 1999.

[28] McGraw J, Van Deventer G, Anton R, et al. Advancements in gas turbine vane repair. In: Proceedings of the ASME 2006 Power Conference, 2006: 385-389.

[29] Kelbassa I, Albus P, Dietrich J, et al. Manufacture and repair of aero engine components using laser technology. In: Proceedings of the 3rd Pacific International Conference on Application of Lasers and Optics, 2008: 208-213.

[30] Fujii T, Takahashi T. Development of operating temperature prediction method using thermophysical properties change of thermal barrier coatings. J Eng Gas Turbines Power 2004, 126: 102-106.

[31] Morinaga M, Fujii T, Takahashi T. Development of actual TBC exposure temperature prediction method. In: Proceedings of the ASME Turbo Expo 2004: Power for Land, Sea, and Air, 2004: 521-526.

[32] Ellingson WA, Koehl ER, Engel HP, et al. Development of nondestructive evaluation methods for structural ceramics. In: Proceedings of the 12th Annual Conference on Fossil Energy Materials, 1998: 270-292.

[33] Clarke DR. Materials selection guidelines for low thermal conductivity thermal barrier coatings. Surf Coat Technol 2003, 163-164: 67-74.

[34] Asakuma Y, Yamamoto T. Thermal analysis of porous medium with ellipsoidal pores using a homogenization method. Heat Mass Transfer 2016, 52: 2113-2117.

[35] Clyne TW, Golosnoy IO, Tan JC, et al. Porous materials for thermal management under extreme conditions. Philos $T$ Roy Soc A 2006, 364: 125-146.

[36] Cernuschi F, Golosnoy IO, Bison P, et al. Microstructural characterization of porous thermal barrier coatings by IR gas porosimetry and sintering forecasts. Acta Mater 2013, 61: $248-262$.

[37] Darolia R. Thermal barrier coatings technology: Critical review, progress update, remaining challenges and prospects. Int Mater Rev 2013, 58: 315-348.

[38] Altun Ö, Böke Y. Heat transfer analyses of thermal barrier coatings on a metal substrate. $J$ Therm Sci Tech 2013, 33: 101-109.

[39] Wang L, Wang Y, Sun XG, et al. Influence of pores on the thermal insulation behavior of thermal barrier coatings prepared by atmospheric plasma spray. Mater Design 2011, 32: $36-47$.

Open Access The articles published in this journal are distributed under the terms of the Creative Commons Attribution 4.0 International License (http://creativecommons. org/licenses/by/4.0/), which permits unrestricted use, distribution, and reproduction in any medium, provided you give appropriate credit to the original author(s) and the source, provide a link to the Creative Commons license, and indicate if changes were made. 